\title{
Intracranial-to-Central Venous Pressure Gap Predicts the Responsiveness of Intracranial Pressure to PEEP in Patients with Traumatic Brain Injury: a Prospective Cohort Study
}

\section{Li Hong Peng}

Ruijin Hospital, Shanghai Jiao Tong University School of Medicine

\section{Lin Ying Ning}

Ruijin Hospital,Shanghai Jiao Tong University of Medicine

Cheng Zhi Hui

Shanghai University of Medicine and Health Sciences Affiliated Zhoupu Hospital

Qu Wei

Shanghai University of Medicine and Health Sciences affiliated Zhoupu Hospital

\section{Zhang Liu}

Ruijin Hospital, Shanghai Jiao Tong University School of Mdedicne

\section{Li Qing Yun ( $\sim$ liqingyun68@hotmail.com )}

Ruijin Hospital, Shanghai Jiao Tong University School of Medicine

\section{Research article}

Keywords: Positive end-expiratory pressure; intracranial pressure; central venous pressure; mechanical ventilation; traumatic brain injury; PICGap

Posted Date: May 12th, 2020

DOI: https://doi.org/10.21203/rs.2.18109/v2

License: (c) (i) This work is licensed under a Creative Commons Attribution 4.0 International License. Read Full License

Version of Record: A version of this preprint was published at BMC Neurology on June 8th, 2020. See the published version at https://doi.org/10.1186/s12883-020-01764-7. 


\section{Abstract}

Background: Mechanical ventilation (MV) with positive end-expiratory pressure (PEEP) is commonly applied in patients with severe traumatic brain injury (sTBI). However, the individual responsiveness of intracranial pressure (ICP) to PEEP varies. Thus, identifying an indicator detecting ICP responsiveness to PEEP is of great significance. As central venous pressure (CVP) could act as an intermediary to transduce pressure from PEEP to ICP, we developed a new indicator, $\mathrm{P}_{\mathrm{IC}} \mathrm{Gap}$, representing the gap between baseline ICP and baseline CVP. The aim of the current study was to explore the relationship between $\mathrm{P}_{\mathrm{IC}} \mathrm{Gap}$ and ICP responsiveness to PEEP.

Methods: A total of 112 patients with STBI undergoing MV were enrolled in this prospective cohort study. ICP, CVP, cerebral perfusion pressure (CPP), static compliance of the respiratory system (Cst), and endtidal carbon dioxide pressure $\left(\mathrm{PetCO}_{2}\right)$ were recorded at the initial $\left(3 \mathrm{cmH}_{2} \mathrm{O}\right)$ and adjusted $\left(15 \mathrm{cmH}_{2} \mathrm{O}\right)$ levels of PEEP. $\mathrm{P}_{\mathrm{IC}}$ Gap was assessed as baseline ICP - baseline CVP (when PEEP $=3 \mathrm{cmH}_{2} \mathrm{O}$ ). The patients were classified into the ICP responder and non-responder groups based on whether ICP increment with PEEP adjusted from $3 \mathrm{cmH}_{2} \mathrm{O}$ to $15 \mathrm{cmH}_{2} \mathrm{O}$ was greater than $20 \%$ of baseline ICP. The above parameters were compared between the two groups, and prediction of ICP responsiveness to PEEP adjustment was evaluated by receiver operating characteristic (ROC) curve analysis.

Results: Compared with the non-responder group, the responder group had lower $\mathrm{P}_{\mathrm{IC}} \mathrm{Gap}(1.63 \pm 1.33$ versus $6.56 \pm 2.46 \mathrm{mmHg} ; p<0.001)$, lower baseline ICP, and higher baseline CVP. ROC curve analysis suggested that $\mathrm{P}_{\mathrm{IC}} \mathrm{Gap}$ was a stronger predictive indicator of ICP responsiveness to PEEP (AUC=0.957, $95 \% \mathrm{Cl}$ 0.918-0.996; $p<0.001)$ compared with baseline ICP and baseline CVP, with favorable sensitivity $(95.24 \%, 95 \% \mathrm{Cl} 86.91 \%-98.70 \%)$ and specificity $(87.6 \%, 95 \% \mathrm{Cl} 75.76 \%-94.27 \%)$, at a cut off value of 2.5 $\mathrm{mmHg}$.

Conclusion: The impact of PEEP on ICP depends on the gap between baseline ICP and baseline CVP, i.e. $\mathrm{P}_{\mathrm{IC}} \mathrm{Gap}$. In addition, $\mathrm{P}_{\mathrm{IC}} \mathrm{Gap}$ is a potential predictor of ICP responsiveness to PEEP adjustment in patients with sTBI.

\section{Background}

Mechanical ventilation (MV) with positive end-expiratory pressure (PEEP) is often required in patients with severe traumatic brain injury (STBI) due to neurologic, airway, and pulmonary dysfunctions $[1,2]$. Application of PEEP during MV is essential to improving oxygenation and protecting from mechanical lung injury, by increasing functional residual capacity, preventing atelectasis, reducing oxygen requirement, and raising static strain component [3-5]. .

However, the influence of PEEP on intracranial pressure (ICP) has been an obstacle to the optimal use of PEEP for a long time [6]. The effect of PEEP on ICP was first mentioned in the later 1970s [7, 8]. In the last three decades, several studies have explored the relationship between PEEP and ICP, but without 
consistent results [1]. Shapiro et al demonstrated that PEEP application in the $4-8 \mathrm{~cm} \mathrm{H}_{2} \mathrm{O}$ range increases ICP $(>10 \mathrm{mmHg})$ [7]. Flexman and colleagues also found that alveolar recruitment maneuvers increase subdural pressure and reduce cerebral perfusion pressure (CPP) in neurosurgery [9]. A recent study by Boone et al found that every centimeter $\mathrm{H}_{2} \mathrm{O}$ increase of PEEP contributes to a $0.31 \mathrm{mmHg}$ increase in ICP [10], and concluded that PEEP might exert adverse effects on cerebral hemodynamics by impeding cerebral venous return and elevating ICP in patients with STBI. However, other studies found no effects of moderate to high levels of PEEP ( $\left.8-25 \mathrm{cmH}_{2} \mathrm{O}\right)$ on ICP, CPP, and CBF in sTBI patients with normal ICP or intracranial hypertension, and PEEP instead exerted favorable effects by improving brain tissue oxygen pressure and saturation [11-14]. Such discrepancy might be related to several factors: (1) individual heterogeneity, mainly involving the severity of and baseline ICP [15]; (2) not fully understood dose-effect relationship between PEEP and ICP; and (3) it is unclear whether PEEP directly affects ICP or indirectly through an intermediate.

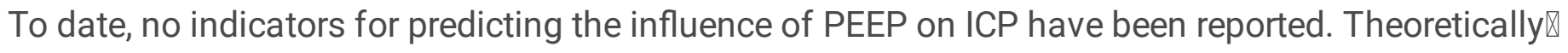
increasing intrathoracic pressure by PEEP may hinder cerebral venous return and increase ICP during MV in patients with STBI, and the relationship between CVP and PEEP has been clarified $[16,17]$. Therefore, we hypothesized that: (1) CVP could act as a mediator between PEEP and ICP; (2) the effect of PEEP on ICP depends on baseline ICP and baseline CVP according to the Starling resistor model (Figure 1). Herein, we developed a new indicator, $\mathrm{P}_{I C} \mathrm{Gap}$, which represents the difference between baseline ICP and baseline CVP (at initial PEEP). The main aim of this study was to explore the predictive efficiency of $\mathrm{P}_{\mathrm{IC}} \mathrm{Gap}$ in ICP responsiveness to PEEP adjustment.

\section{Methods}

\section{Study design and setting}

This prospective study was conducted between May 2016 and May 2019 in the intensive care unit (ICU) of Zhoupu Hospital affiliated to Shanghai University of Medicine \& Health Sciences. It has been registered at ClinicalTrials.gov (NCT03296293), and approval of the study protocol was granted by the clinical research ethics committee of Zhoupu Hospital (no. ZPYYLL-2016-12). Written informed consent was obtained from the legal representatives of all patients upon admission because of the coma state of the enrolled study patients.

\section{Study participants}

All patients with sTBI (Glasgow Coma Scale $[\mathrm{GCS}] \leq 8$ ) diagnosed via head CT scan, ICP monitoring transducers or catheter, hypoxemia $\left(\mathrm{SpO}_{2}<90 \%\right)$ and MV (Dräger Infinity C500, Dräger, Germany) were initially included. The patients whose hypoxemia could not be corrected even by increasing the $\mathrm{FiO}_{2}$ by more than $60 \%$ in combination with suction and intensive airway management were eventually enrolled. Exclusion criteria included brain death, age below 18 or over 80 years, pregnancy in women, hemodynamic instability [heart rate $>120$ bpm or CPP (calculated as MAP-ICP) $<60 \mathrm{mmHg}$, 
pneumothorax, pulmonary bulla, acute myocardial infarction (elevated cardiac troponin T more than 3 times the normal upper limit accompanied by the ST-T change) and neurosurgical intervention.

\section{Treatment and data measurements}

The treatment process followed the Guidelines for the Management of sTBI [18]. All patients were placed in the supine position at 30 degrees head of bed elevation and deeply sedated $(0.05 \mathrm{mg} / \mathrm{kg}$ loading dose, followed by continuous intravenous infusion of midazolam at $0.05-0.3 \mathrm{mg} / \mathrm{kg} / \mathrm{h}$ and sufentanil at 0.2 $\mu \mathrm{g} / \mathrm{kg} / \mathrm{h}$ ) to maintain a Richmond Agitation-Sedation Scale (RASS) score of -5 and, thus, to remove the effects of cough and other neuronal and confounding factors on ICP. The ventilator settings remained consistent for all enrolled patients. The tidal volume was adjusted and maintained at $8 \mathrm{~mL} / \mathrm{kg}$ of the predicted body weight, and the plateau pressure was maintained below $30 \mathrm{cmH}_{2} \mathrm{O}$. Support pressure was maintained at 12-14 $\mathrm{cm} \mathrm{H}_{2} \mathrm{O}$; initial PEEP was set at $3 \mathrm{cmH}_{2} \mathrm{O}$, and fraction of inspired oxygen $\left(\mathrm{FiO}_{2}\right)$ was set at $35 \%-50 \%$ to maintain a pulse oxygen saturation $\left(\mathrm{SpO}_{2}\right) 90 \%$. ICP was continuously monitored (Codman ICP ExpressTM, Johnson, USA) through an intraparenchimal transducer or a ventricular catheter (Codman ICP Transducer, Johnson, USA) that was associated with a closed external ventricular drain in each measurement when applicable. Both central venous and arterial catheters were inserted to measure intra-arterial MAP and CVP. CPP was maintained at more than $60-65 \mathrm{mmHg}$. The static compliance of the respiratory system (Cst) recorded from the ventilator was indexed to the predicted body weight of the patient. During the study, end-tidal carbon dioxide pressure $\left(\mathrm{PetCO}_{2}\right)($ monitoring by Drager Mainstream $\mathrm{CO}_{2}$ device, SN: ASHM-0552, Dräger, Germany) was maintained at $30-35 \mathrm{mmHg}$ by adjusting tidal volume and the respiratory rate, in order to avoid any effect of $\mathrm{CO}_{2}$ on ICP [19].

The stepwise increase of PEEP was set according to a method by Lim et al [20] when hypoxemia persisted. Briefly, $100 \%-\mathrm{FiO}_{2}$ was set, and PEEP was increased stepwise (from $3 \mathrm{cmH}_{2} \mathrm{O}$ to $10 \mathrm{cmH}_{2} \mathrm{O}$, and to $15 \mathrm{cmH}_{2} \mathrm{O}$ ) every $2 \mathrm{~min}$, which was a recruitment maneuver known as "extended sigh". ICP, CVP, Cst, PetCO $_{2}$, and CPP at both levels of PEEP $\left(3 \mathrm{cmH}_{2} \mathrm{O}\right.$ and $\left.15 \mathrm{cmH}_{2} \mathrm{O}\right)$ were measured, respectively. After PEEP at $15 \mathrm{cmH}_{2} \mathrm{O}$ was maintained for 2 min, baseline ventilator setting was resumed.

Based on our research hypothesis and the specific relationship between CVP and PEEP [16, 17], PIC Gap and other measurements (Cst, CPP, ICP, and $\mathrm{PetCO}_{2}$ ) were compared between the responder and nonresponder groups, and prediction of ICP responsiveness to PEEP was tested by assessing the area under the receiver operating characteristic (ROC) curve (AUC).

In this study, treatment was provided in case of: (1) $\mathrm{CPP}<60 \mathrm{mmHg}$ (norepinephrine $0.3-1.0 \mu \mathrm{g} / \mathrm{kg} / \mathrm{min}$ ); (2) ICP > $25 \mathrm{mmHg}$ (PEEP was restored to 0); (3) increase in pressure plateau $>35 \mathrm{cmH}_{2} \mathrm{O}$ (tidal volume was decreased and the respiratory rate was increased to maintain $\mathrm{PetCO}_{2}$ at $30-35 \mathrm{mmHg}$ ); (4) $\mathrm{SpO}_{2}$ declined progressively (PEEP was restored to 0); and (5) suspicion of pneumothorax (PEEP was restored to 0 , and chest radiography was undertaken). An equilibration period ( $\geq 90 \mathrm{~s})$ was entailed to ensure a 
normalized baseline $\mathrm{PetCO}_{2}$ through tidal volume and respiratory rate modulation, as described by Flexman and colleagues [21].

\section{Study Outcomes}

The main outcome was ICP responsiveness to PEEP adjustment from $3 \mathrm{cmH}_{2} \mathrm{O}$ to $15 \mathrm{cmH}_{2} \mathrm{O}$. Because there is no specified definition for ICP responsiveness, we stipulated that response and non-response referred to increments greater than and less than $20 \%$ of baseline ICP, respectively. The patients were then classified into the responder and non-responder groups accordingly.

\section{Statistical analysis}

Categorical variables were presented as number and percentage, and analyzed by Fisher's exact test. Continuous covariates, including hemodynamic variables ICP, CVP, CPP, Cst, PetCO ${ }_{2}$ and CPP, were expressed as mean \pm standard error. One-way analysis of variance (ANOVA) followed by Bonferroni post hoc test was used for multiple comparisons. The predictive roles of $\mathrm{P}_{\mathrm{IC}} \mathrm{Gap}$ other related parameters recorded for ICP responsiveness to PEEP were tested by calculating the AUCs of the ROC curves of ICP over the baseline value at two levels of PEEP ( 3 and $\left.15 \mathrm{cmH}_{2} \mathrm{O}\right) . P<0.05$ was considered statistically significant. All statistical analyses were performed with SPSS 20.0 for windows (IBM Co. NY, USA).

\section{Results}

1. Patients baseline characteristics between responder group and non-responder group.

From May 2016 to May 2019, a total of 174 patients were included initially. 62 patients were excluded for hemodynamic instability neurosurgical interventions before admission of ICU, and hypoxemia corrected by suction and increase of $\mathrm{FiO}_{2}$, and 112 were entered into the final analysis (supplementary materials, Figure Flowchart). Baseline characteristics of the study population in the responder $(n=49)$ and nonresponder $(n=63)$ groups are shown in Table 1.

Compared with the non-responder group, the responder group had lower $\mathrm{P}_{\mathrm{IC}} \mathrm{Gap}(1.63 \pm 1.33$ versus $6.56 \pm 2.46 \mathrm{mmHg} ; p<0.001)$, lower baseline ICP $(9.82 \pm 2.97$ versus $13.10 \pm 2.74 \mathrm{mmHg}, p<0.001)$, and higher baseline CVP $(8.18 \pm 2.66$ versus $6.54 \pm 2.59 \mathrm{mmHg}, p=0.001)$.

2. Effects of PEEP adjustment on CVP, CVP increment and ICP in the responder and non-responder groups.

Adjustment of PEEP from 3 to $15 \mathrm{cmH}_{2} \mathrm{O}$ increased CVP levels significantly in both groups (Figure $2 \mathrm{~A}$ ). There were no significantly differences in CVP increment $(\triangle \mathrm{CVP})$ between the responder and nonresponder groups $(4.39 \pm 1.30$ versus $4.25 \pm 1.58 \mathrm{mmHg} ; p=0.174)$ (Figure $2 \mathrm{~B})$. A significant ICP increase was observed in the responder group with PEEP tuned up from $3 \mathrm{cmH}_{2} \mathrm{O}$ to $15 \mathrm{mmHg}(9.85 \pm 2.99$ versus 
$14.48 \pm 3.22 \mathrm{mmHg} ; p<0.001)$, with no change in the non-responder group $(13.10 \pm 2.74$ versus $13.71 \pm 2.61$ $\mathrm{mmHg} ; p=0.196)$ (Figure 2C).

No severe side effects in terms of ICP, CVP, CPP, and MAP were observed when PEEP was increased to 15 $\mathrm{cmH}_{2} \mathrm{O}$ (supplementary materials, Table E1).

3. Predictive role of $P_{I C} G a p$, baseline ICP, and baseline CVP on the responsiveness of ICP to PEEP adjustment.

As shown in Table 1, $\mathrm{P}_{\mathrm{IC}}$ Gap, baseline ICP, and baseline CVP were significantly different between the responder and non-responder groups, and no significant differences were found in the other variables tested. The predictive abilities of $\mathrm{P}_{\mathrm{IC}} \mathrm{Gap}$, baseline ICP, and baseline CVP were assessed through ROC analysis. As shown in Figure 3, $\mathrm{P}_{\mathrm{IC}} \mathrm{Gap}$ had the strongest predictive ability for ICP responsiveness to PEEP increase (AUC=0.957, 95\% $\mathrm{Cl} 0.918-0.996 ; p<0.001)$ among the three parameters. At a cut off value of 2.5 $\mathrm{mmHg}, \mathrm{P}_{\mathrm{IC}} \mathrm{Gap}$ had favorable sensitivity $(95.24 \%, 95 \% \mathrm{Cl} 86.91 \%-98.70 \%)$ and specificity $(87.6 \%, 95 \% \mathrm{Cl}$ 75.76\%-94.27\%) in predicting ICP responsiveness to PEEP. However, baseline ICP had an overtly weaker predictive ability compared with $\mathrm{P}_{\mathrm{IC}} \mathrm{Gap}(\mathrm{AUC}=0.782,95 \% \mathrm{Cl} 0.693-0.781 ; p<0.001)$, and baseline CVP had the weakest ability for predicting ICP responsiveness among the three parameters (AUC $=0.660,95 \% \mathrm{Cl}$ $0.560-0.760 ; p=0.004)$.

\section{Discussion}

In the present study, in agreement with our hypothesis that CVP may be an intermediary that delivers pressure from PEEP to ICP, we found that ICP was increased after PEEP only with baseline ICP close to CVP, i.e. $P_{\mathrm{IC}} \mathrm{Gap}$ was narrower in the responder group compared with the non-responder group $(1.63 \pm 1.33$ versus $6.55 \pm 2.46 \mathrm{mmHg})$. This indicates that the same increment of CVP $(4.39 \pm 1.30$ versus $4.25 \pm 1.58$ $\mathrm{mmHg}$ ) could obliterate $\mathrm{P}_{\mathrm{IC}} \mathrm{Gap}$ in the responder group, but not in non-responders (Figure 1). We also evaluated whether $P_{I C} G a p$, baseline ICP, and baseline CVP could predict ICP responsiveness to PEEP in patients with sTBI. The results suggested that $\mathrm{P}_{\mathrm{IC}} \mathrm{Gap}$ was the strongest predictive indicator among the three parameters. $P_{I C}$ Gap less than $2.5 \mathrm{mmHg}$ could predict ICP responsiveness to PEEP tuned up to 15 $\mathrm{cmH}_{2} \mathrm{O}$. To the best of our best knowledge, this is the first study demonstrating that PEEP-induced changes of ICP depend on $\mathrm{P}_{\mathrm{IC}}$ Gap rather than PEEP itself.

Although cerebral hemodynamics is not governed entirely by extradural venous pressure since normal ICP $(8-13 \mathrm{mmHg})$ is higher than the venous pressure outside the dura $(0-5 \mathrm{mmHg})$, the changes of extradural venous pressure transfer to the brain circulation might rely on a certain situation [22]. The degree of subdural venous collapse was related to the difference between ICP and extradural venous pressure, and this passive collapse acts as a variable venous outflow resistance. An alteration of extradural venous pressure causes up- or downregulation of venous outflow resistance through the self-regulation of the degree of passive collapse according to the Starling resistor model [23]. 
CVP could act as a surrogate marker of extradural venous pressure, because the pressure falling on the jugular vein is negligible in the supine position. A preliminary experiment also showed that CVP values were the same as those of jugular bulb pressure. According to the Starling resistor model [23], once the value of CVP after PEEP exceeds baseline ICP, venous outflow resistance would be downregulated to the lower limit. In such a situation, the brain circulation would be impeded, with ICP rising accordingly.

The relationship between PEEP and CVP has been validated by previous studies. Stepwise PEEP elevation induces an increase of CVP [17]. An increase of $12 \mathrm{cmH}_{2} \mathrm{O}$ in PEEP caused a more than 4 $\mathrm{mmHg}$ rise of CVP in the current study, which was consistent with previous findings [17]. Thus, it is reasonable to infer that PEEP directly increases CVP, and whether CVP after PEEP could increase ICP depends on the extent of $\mathrm{P}_{\mathrm{IC}} \mathrm{Gap}$ narrowing by CVP.

The lower the $\mathrm{P}_{\mathrm{IC}} \mathrm{Gap}$, the easier it is for CVP after PEEP to exceed baseline ICP; then, the Starling resistor would lose effectiveness as a result of the elimination of venous outflow resistance. As indicated in Table 1 , patients with responsiveness to PEEP adjustment had relatively lower $P_{I C}$ Gap compared with the nonresponder group. Thus, based on the hypothesis that CVP is an intermediary which connects PEEP to ICP, we found that $P_{I C} G A P$, a new indicator, could provide a rational explanation regarding the underlying mechanism, which also accounts for the individual heterogeneity proposed by Yang and colleagues [15].

Brain compliance is unfavorable in patients with STBI because of cerebral edema associated with injury. In this case, cerebral venous return impeded by increased CVP after PEEP would contribute to increasing ICP after $\mathrm{P}_{\mathrm{IC}} \mathrm{Gap}$ is narrowed to zero. A study by Robba and colleagues investigated the effects of pneumoperitoneum and the Trendelenburg position on ICP in non-brain injured patients (lower ICP), and demonstrated that both increase ICP [24]. There was no significant change in arterial blood pressure and CPP in the study. Although CVP was not monitored, increased ICP might be due to an obstruction of cerebral venous return theoretically [25].

Several studies used baseline ICP to predict the responsiveness of ICP to PEEP, and found that patients with lower baseline ICP have a positive response to various PEEP levels [26, 27]. These results were consistent with our findings. Individuals with elevated mean baseline ICP experienced no significant changes of ICP during PEEP alteration. However, these studies have not clarified that a certain ICP value could predict ICP responsiveness to PEEP. Our results also showed that baseline ICP was not a more efficient predictive indicator compared with $\mathrm{P}_{\mathrm{IC}}$ Gap.

It should be mentioned that ICP responsiveness to PEEP may be influenced by compliance of the respiratory system $[28,29]$. Assessment of patients with low-compliance lungs showed that cerebral hemodynamics and ICP are not influenced by the application of PEEP, because less compliance may not transmit the increased pressure to the entire intrathoracic space effectively. In the current study, all the enrolled patients had normal compliance (Table 1). In addition, recent studies have challenged the effects of PEEP on ICP, arguing that PEEP may be more related to eventual changes in hemodynamics or lung compliance than affecting CVP [30-32]. For example, it was proposed that ICP markedly increases after 
PEEP application, but only in case PEEP induces alveolar hyperinflation with subsequent $\mathrm{PaCO}_{2}$ increase [30].

It is known that STBI patients tend to progress rapidly early after injury; therefore, they were kept in the ICU for 24 hours after injury for close monitoring of ICP in this study. To prevent catheter-related infections, the ICP monitoring probe was implanted for no more than 7 days. In case of hypoxemia, increased PEEP was provided for lung recruitment and increased oxygen saturation. The purpose of a PEEP of $15 \mathrm{cmH}_{2} \mathrm{O}$ during lung recruitment was to avoid the harmful effects of high PEEP $\left(>20 \mathrm{cmH}_{2} \mathrm{O}\right)$, such as worsened hemodynamics and significantly increased ICP. Consequently, no serious complication was recorded in this study (Table E1). In addition, maintaining PEEP at $15 \mathrm{cmH}_{2} \mathrm{O}$ for 2 minutes helped achieve pulmonary bloating [20] and normalize $\mathrm{PetCO}_{2}$ to avoid the impact of $\mathrm{CO}_{2}$ retention on ICP [21]. PEEP in this study did not adversely affect hemodynamics in both patient groups (Table E1), and there was no significant difference in prognosis between the two groups (Table E2).

The limitations of this study should be mentioned. First, the sample size was relatively small for a clinical study. In addition, the effect of PEEP on CBF was not evaluated. However, we maintained $\mathrm{PetCO}_{2}$ at the normal level, and ICP elevation was in a permissible range, indicating likely stable CBF. Furthermore, although $\mathrm{P}_{\mathrm{IC}} \mathrm{Gap}$ is a dynamic marker, it did not change dramatically in the early stage of TBI in certain patients after neurosurgery, ensuring the predictive value individually.

\section{Conclusions}

The impact of PEEP on ICP depends on the gap between baseline ICP and CVP. $\mathrm{P}_{\mathrm{IC}} \mathrm{Gap}$, a new indicator, could be a potential predictor of ICP responsiveness to PEEP adjustment in patients with sTBI.

\section{Declarations}

\section{Ethics approval and consent to participate}

The study protocol was approved by the clinical research ethics committee of Shanghai University of Medicine \& Health Sciences Affiliated Zhoupu Hospital (ZPYYLL-2016-12). Written consent was obtained from all participants' legal representatives because the enrolled patients were in a coma state.

\section{Consent for publication}

Not applicable.

\section{Availability of data and materials}

The datasets used and/or analyzed in the present study are available from the corresponding author on reasonable request. 


\section{Competing interests}

The authors declare they have no potential conflicts of interest relevant to this research work. Funding

The present study was supported in part by the seed fund program of Shanghai University of Medicine \& Health Sciences (grant number HMSF-17-22-041), the Key Research Program of Shanghai Science and Technology Commission (grant number 18140903600), and Shanghai Key Discipline for Respiratory Disease (grant number 2017ZZ02014). The funders had no role in study design, data collection and analysis, decision to publish, or preparation of the manuscript.

\section{Authors' contributions}

H P L, Y N L, Z H C, and Q Y L planned and performed the experiments, supervised the study, analyzed the data and drafted the manuscript. L Zand W Q participated in performing the experiments. All authors read and approved the final version of the manuscript.

\section{Acknowledgements}

Not Applicable

\section{Publisher's Note}

Springer Nature remains neutral with regard to jurisdictional claims in published maps and institutional affiliations.

\section{Author details}

${ }^{1}$ Department of Respiratory and Critical Care Medicine, Ruijin Hospital, Shanghai Jiao Tong University School of Medicine, Shanghai 200025, PR China冈Institute of Respiratory Medicine, Shanghai Jiao Tong University School of Medicine, Shanghai 200025, PR China.

2 Department of Emergency and Critical Care Medicine, Shanghai University of Medicine \& Health Sciences Affiliated Zhoupu Hospital, Shanghai 201318, PR China

\section{References}

1. Chiumello D, Chidini G, Calderini E, Colombo A, Crimella F, Brioni M. Respiratory mechanics and lung stress/strain in children with acute respiratory distress syndrome. Ann Intensive Care. 2016; 6(1):11.

2. Protti A, Andreis DT, Monti M, Santini A, Sparacino CC, Langer T, Votta E, Gatti S, Lombardi L, Leopardi O, Masson S, Cressoni M, Gattinoni L. Lung stress and strain during mechanical ventilation: Any difference between statics and dynamics? Crit Care Med. 2013; 41(4):1046-55. 
3. Borsellino B, Schultz MJ, Gama DAM, Robba C, Bilotta F. Mechanical ventilation in neurocritical care patients: A systematic literature review. Expert Rev Respir Med. 2016; 10(10):1123-32.

4. Hendrickson CM, Howard BM, Kornblith LZ, Conroy AS, Nelson MF, Zhuo H, Liu KD, Manley GT, Matthay MA, Calfee CS, Cohen MJ. The acute respiratory distress syndrome following isolated severe traumatic brain injury. J Trauma Acute Care Surg. 2016; 80(6):989-97.

5. Briel M, Meade M, Mercat A, Brower RG, Talmor D, Walter SD, Slutsky AS, Pullenayegum E, Zhou Q, Cook D, Brochard L, Richard JC, Lamontagne F, Bhatnagar N, Stewart TE, Guyatt G. Higher vs lower positive end-expiratory pressure in patients with acute lung injury and acute respiratory distress syndrome: Systematic review and meta-analysis. JAMA. 2010; 303(9):865-73.

6. Koutsoukou A, Katsiari M, Orfanos SE, Kotanidou A, Daganou M, Kyriakopoulou M, Koulouris NG, Rovina N. Respiratory mechanics in brain injury: A review. World J Crit Care Med. 2016; 5(1):65-73.

7. Apuzzo JL, Wiess MH, Petersons V, Small RB, Kurze T, Heiden JS. Effect of positive end expiratory pressure ventilation on intracranial pressure in man. J Neurosurg. 1977; 46(2):227-32.

8. Shapiro HM, Marshall LF. Intracranial pressure responses to PEEP in head-injured patients. J Trauma. 1978; 18(4):254-6.

9. Flexman AM, Gooderham PA, Griesdale DE, Argue R, Toyota B. Effects of an alveolar recruitment maneuver on subdural pressure, brain swelling, and mean arterial pressure in patients undergoing supratentorial tumour resection: A randomized crossover study. Can J Anaesth. 2017; 64(6):626-33.

10. Boone MD, Jinadasa SP, Mueller A, Shaefi S, Kasper EM, Hanafy KA, O'Gara BP, Talmor DS. The effect of positive End-Expiratory pressure on intracranial pressure and cerebral hemodynamics. Neurocrit Care. 2017; 26(2):174-81.

11. Nemer SN, Caldeira JB, Santos RG, Guimaraes BL, Garcia JM, Prado D, Silva RT, Azeredo LM, Faria ER, Souza PC. Effects of positive end-expiratory pressure on brain tissue oxygen pressure of severe traumatic brain injury patients with acute respiratory distress syndrome: A pilot study. J Crit Care. 2015; 30(6):1263-6.

12. Muench E, Bauhuf $C$, Roth $H$, Horn P, Phillips M, Marquetant N, Quintel M, Vajkoczy P. Effects of positive end-expiratory pressure on regional cerebral blood flow, intracranial pressure, and brain tissue oxygenation. Crit Care Med. 2005; 33(10):2367-72.

13. Ropper AH, O'Rourke D, Kennedy SK. Head position, intracranial pressure, and compliance. Neurology. 1982; 32(11):1288-91.

14. De Rosa S, Villa G, Franchi P, Mancino A, Tosi F, Martin MA, Bazzano S, Conti G, Pulitano SM. Impact of positive end expiratory pressure on cerebral hemodynamic in paediatric patients with posttraumatic brain swelling treated by surgical decompression. Plos One. 2018; 13(5):e196980.

15. Yang ZJ, Zhang XY, Shen JF, Wang QX, Fan HR, Jiang X, Chen L. the impact of positive endexpiratory pressure on cerebral perfusion pressure and hemodynamics in patients receiving lung recruitment maneuver. Zhongguo Wei Zhong Bing Ji Jiu Yi Xue (Chinese). 2008; 20(10):588-91.

16. Shojaee M, Sabzghabaei A, Alimohammadi H, Derakhshanfar H, Amini A, Esmailzadeh B. Effect of Positive End-Expiratory Pressure on Central Venous Pressure in Patients under Mechanical 
Ventilation. Emerg (Tehran). 2017; 5(1):e1.

17. Cao F, Liu XF, Chen RL, Wang XC. Effect of positive end-expiratory pressure on central venous pressure and common iliac venous pressure in mechanically ventilated patients. Zhongguo Wei Zhong Bing Ji Jiu Yi Xue (Chinese). 2008; 20(6):341-4.

18. Carney N, Totten AM, O'Reilly C, Ullman JS, Hawryluk GW, Bell MJ, Bratton SL, Chesnut R, Harris OA, Kissoon N, Rubiano AM, Shutter L, Tasker RC, Vavilala MS, Wilberger J, Wright DW, Ghajar J. Guidelines for the management of severe traumatic brain injury, fourth edition. Neurosurgery. 2017; $80(1): 6-15$.

19. Lee JS, Nam SB, Chang CH, Han DW, Lee YW, Shin CS. Relationship between arterial and end-tidal carbon dioxide pressures during anesthesia using a laryngeal tube. Acta Anaesthesiol Scand. 2005; 49(6):759-62.

20. Lim CM, Koh Y, Park W, Chin JY, Shim TS, Lee SD, Kim WS, Kim DS, Kim WD. Mechanistic scheme and effect of "extended sigh" as a recruitment maneuver in patients with acute respiratory distress syndrome: A preliminary study. Crit Care Med. 2001; 29(6):1255-60.

21. Flexman AM, Gooderham PA, Griesdale DE, Argue R, Toyota B. Effects of an alveolar recruitment maneuver on subdural pressure, brain swelling, and mean arterial pressure in patients undergoing supratentorial tumour resection: A randomized crossover study. Can J Anaesth. 2017; 64(6):626-33.

22. Grande PO. The "Lund Concept" for the treatment of severe head trauma-physiological principles and clinical application. Intensive Care Med. 2006; 32(10):1475-84.

23. Kongstad L, Grande PO. The role of arterial and venous pressure for volume regulation of an organ enclosed in a rigid compartment with application to the injured brain. Acta Anaesthesiol Scand. 1999; 43(5):501-8.

24. Robba C, Cardim D, Donnelly J, Bertuccio A, Bacigaluppi S, Bragazzi N, Cabella B, Liu X, Matta B, Lattuada M, Czosnyka M. Effects of pneumoperitoneum and Trendelenburg position on intracranial pressure assessed using different non-invasive methods. Br J Anaesth. 2016; 117(6):783-91.

25. Schoser BG, Riemenschneider N, Hansen HC. The impact of raised intracranial pressure on cerebral venous hemodynamics: A prospective venous transcranial Doppler ultrasonography study. J Neurosurg. 1999; 91(5):744-9.

26. McGuire G, Crossley D, Richards J, Wong D. Effects of varying levels of positive end-expiratory pressure on intracranial pressure and cerebral perfusion pressure. Crit Care Med. 1997; 25(6):105962.

27. Cooper KR, Boswell PA, Choi SC. Safe use of PEEP in patients with severe head injury. J Neurosurg. $1985 ; 63(4): 552-5$.

28. Caricato A, Conti G, Della CF, Mancino A, Santilli F, Sandroni C, Proietti R, Antonelli M. Effects of PEEP on the intracranial system of patients with head injury and subarachnoid hemorrhage: The role of respiratory system compliance. J Trauma. 2005; 58(3):571-6.

29. Chen H, Chen K, Xu JQ, Zhang YR, Yu RG, Zhou JX. Intracranial pressure responsiveness to positive end-expiratory pressure is influenced by chest wall elastance: A physiological study in patients with 
aneurysmal subarachnoid hemorrhage. Bmc Neurol. 2018; 18(1):124.

30. Robba C, Bonatti G, Battaglini D, Rocco PRM, Pelosi P. Mechanical ventilation in patients with acute ischaemic stroke: from pathophysiology to clinical practice. Crit Care. 2019; 23(1):388.

31. Tejerina E, Pelosi P, Muriel A, Tejerina E, Pelosi P, Muriel A, Penuelas O, Sutherasan Y, Frutos-Vivar F, Nin N, Davies AR, Rios F, Violi DA, Raymondos K, Hurtado J, Gonzalez M, Du B, Amin P, Maggiore SM, Thille AW, Soares MA, Jibaja M, Villagomez AJ, Kuiper MA, Koh Y, Moreno RP, Zeggwagh AA, Matamis D, Anzueto A, Ferguson ND, Esteban A. Association between ventilatory settings and development of acute respiratory distress syndrome in mechanically ventilated patients due to brain injury. J Crit Care. 2017; 38:341-5.

32. Robba C, Bragazzi NL, Bertuccio A, Cardim D, Donnelly J, Sekhon M, Lavinio A, Duane D, Burnstein R, Matta B, Bacigaluppi S, Lattuada M, Czosnyka M. Effects of Prone Position and Positive EndExpiratory Pressure on Noninvasive Estimators of ICP: A Pilot Study. J Neurosurg Anesthesiol. 2017; 29(3):243-50.

\section{Tables}

Table E1. PEEP of $15 \mathrm{cmH}_{2} \mathrm{Onanandbetween} \mathrm{responder} \mathrm{group} \mathrm{and} \mathrm{non-responder} \mathrm{group.}$

\begin{tabular}{|c|c|c|c|}
\hline & Responder group $(\mathrm{n}=49)$ & Non-Responder group $(\mathrm{n}=63)$ & $\bar{p}$ \\
\hline \multicolumn{4}{|l|}{ Hemodynamics variables } \\
\hline CVP, mmHg, mean (SD) & $13.35(3.01)$ & $10.76(3.70)$ & $<0.001$ \\
\hline MAP, mmHg, mean (SD) & $80.18(5.28)$ & $78.29(6.43)$ & 0.097 \\
\hline $\mathrm{HR}, \mathrm{bpm}$, mean (SD) & $79.34(15.61)$ & $82.29(16.54)$ & 0.084 \\
\hline ICP, mmHg, mean (SD) & $14.45(3.20)$ & $13.71(2.61)$ & 0.183 \\
\hline $\mathrm{CPP}, \mathrm{mmHg}$, mean (SD) & $65.73(4.58)$ & $64.57(5.82)$ & 0.253 \\
\hline $\mathrm{PetCO}_{2}, \mathrm{mmHg}$ & $33.73(3.11)$ & $33.43(3.07)$ & 0.604 \\
\hline $\mathrm{CrsI}, \mathrm{ml} / \mathrm{kg} / \mathrm{cmH}_{2} \mathrm{O}$ & $1.30(0.05)$ & $1.29(0.05)$ & 0.243 \\
\hline
\end{tabular}

CVP, central venous pressure; MAP, mean arterial pressure; HR, heart rate; ICP, intracranial pressure; CPP, cerebral perfusion pressure; $\mathrm{PetCO}_{2}$, end-tidal carbon dioxide pressure; CstI, the static compliance of respiratory system (Cst) indexed to the predicted body weight of the patients.

Table E2 Comparison of prognosis between two groups

\begin{tabular}{llll}
\hline & Responder group $(\mathrm{n}=49)$ & Non-Responder group $(\mathrm{n}=63)$ & $p$ \\
\hline ICU stay, day, mean (SD) & $12.41(2.16)$ & $13.69(2.24)$ & 0.104 \\
MV duration, day, mean (SD) & $6.35(3.20)$ & $7.76(3.91)$ & 0.079 \\
\hline Neurosurgical interventions, $\mathrm{n},(\%)$ & $11(22.44)$ & $16(25.40)$ & 0.096 \\
\hline Mortality of 28 days, n, (\%) & $5(10.20)$ & $7(11.11)$ & 0.871 \\
\hline
\end{tabular}

intensive care unit; MV, mechanical ventilation

\section{Figures}




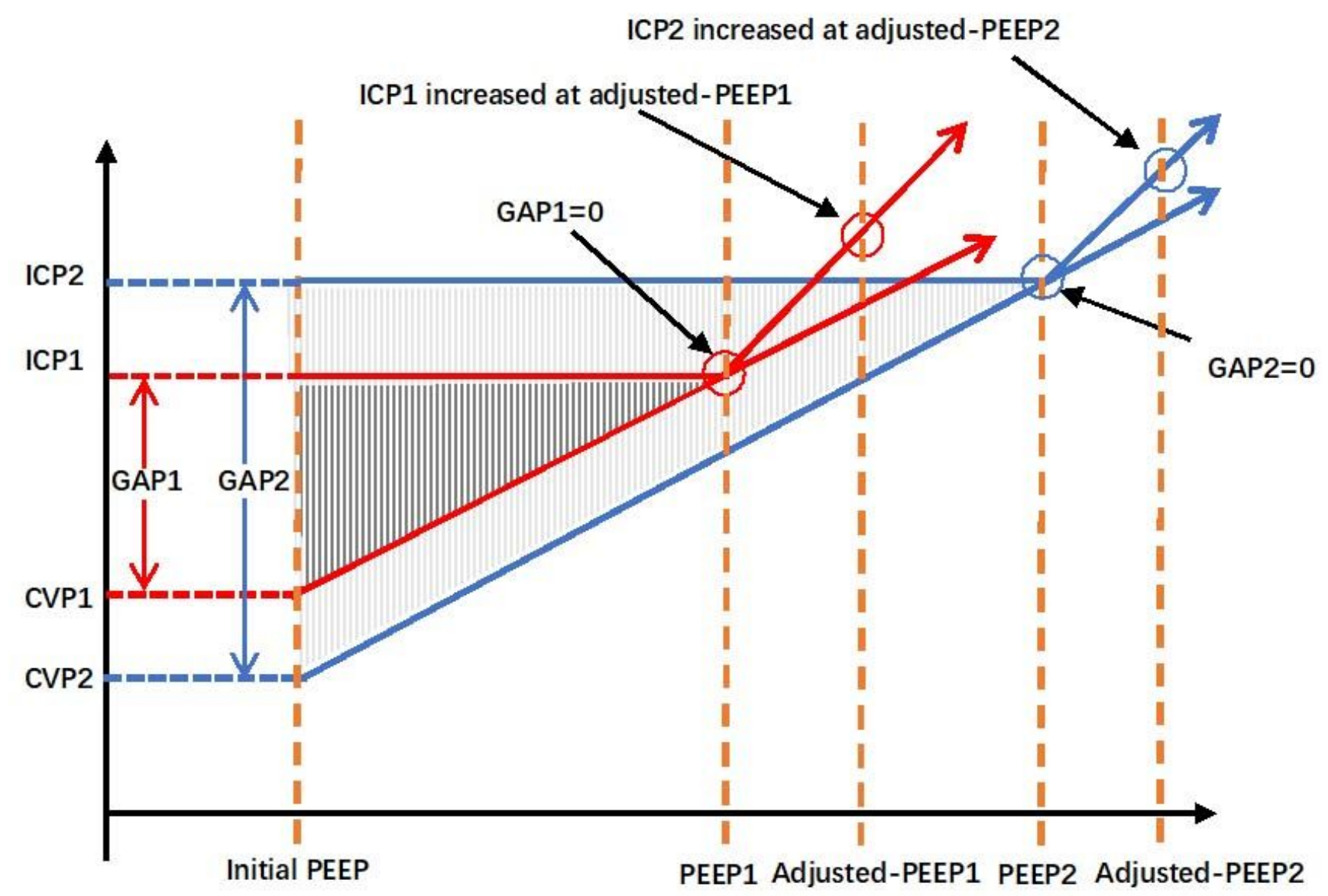

\section{Figure 1}

Schematic diagram for research hypothesis. CVP1 and CVP2 increased from baseline value when PEEP was elevated from initial PEEP, however, ICP1 and ICP2 remained unchanged in the beginning. Thus, GAP1 and GAP2 got narrowed gradually till disappeared when PEEP reached up to PEEP1 and PEEP2 (see dark grey shade and light grey shade). PEEP1 and PEEP2 were critical pressure (this moment, GAP1 $=0$ and GAP2 $=0$ ) for patient $A$ and patient $B$ respectively, and thereafter, CVP1 at adjusted-PEEP1 would exceed the value of baseline ICP which would contribute to elevation of ICP1, and likewise for CVP2 at adjusted-PEEP2. Value of CVP and ICP at initial PEEP were termed baseline ICP and baseline CVP respectively (the same below). ICP1 and CVP1 represented intracranial pressure and central venous pressure at different levels of PEEP for patient A. ICP2 and CVP2 referred to intracranial pressure and central venous pressure at for patient B. GAP1 and GAP2 were calculated by ICP1-CVP1 and ICP2-CVP2. PEEP mean positive end-expiratory pressure. 

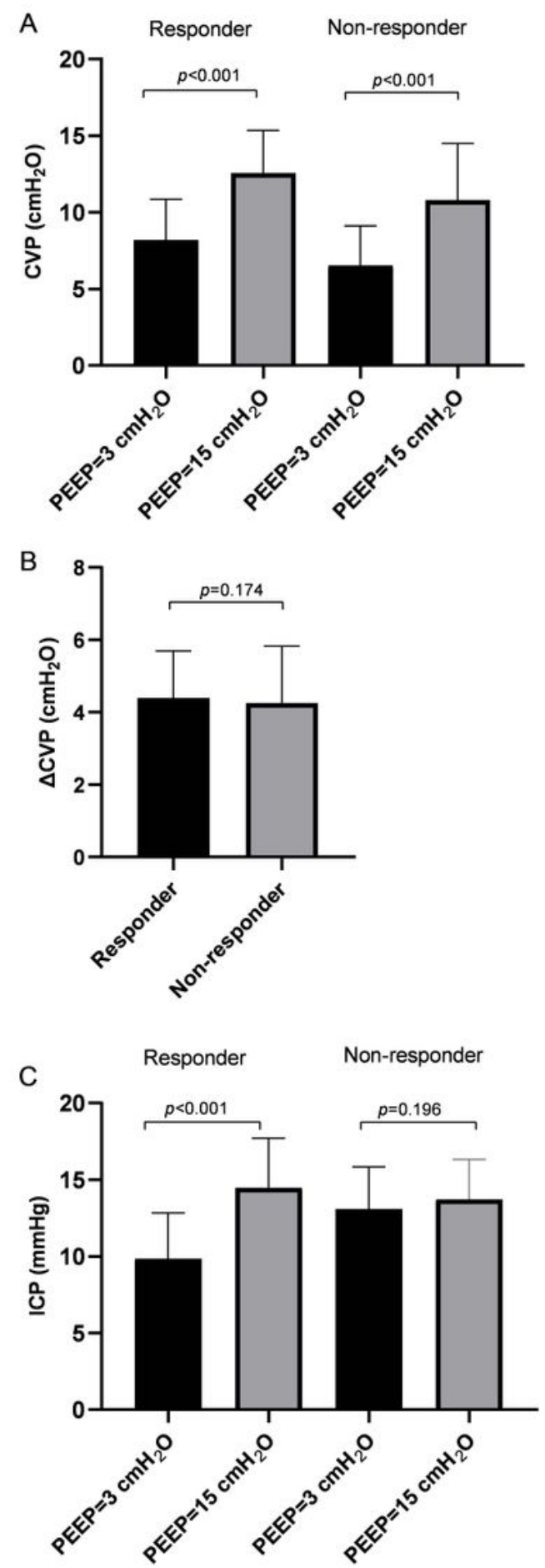

\section{Figure 2}

Effects of PEEP adjustment on CVP and ICP between responder group and non-responder group. Adjustment of PEEP from 3 to $15 \mathrm{cmH} 20$ increased the levels of CVP significantly in two groups (Figure $1 A)$. There were no significantly difference in increment of CVP ( $\triangle C V P)$ between responder group and non-responder group (Figure 1B). A significant increasing of ICP was observed in responder group when 
PEEP tuned up from $3 \mathrm{cmH} 2 \mathrm{O}$ to $15 \mathrm{mmHg}$ and no change in non-responder group (Figure 1C) PEEP, positive end-expiratory pressure; ICP, intracranial pressure; CVP, central venous pressure.

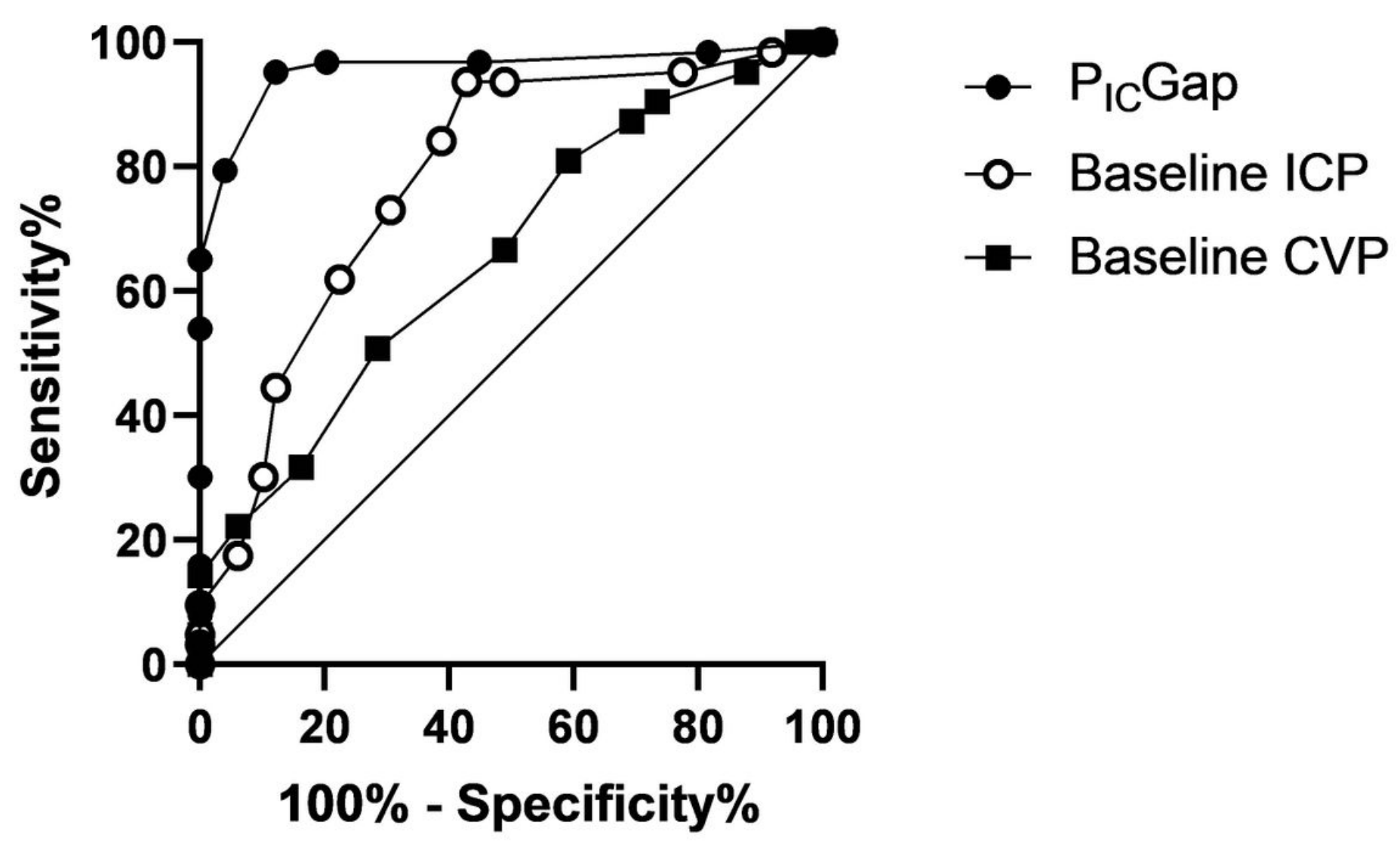

Figure 3

The predictive role of PICGap, baseline ICP, and baseline CVP for ICP responsiveness to PEEP: AUC of ROC for predicting ICP responsiveness to PEEP adjustment. PICGap had a strongest ability to predict the responsiveness of ICP to PEEP increase (AUC $=0.957,95 \% \mathrm{Cl}: 0.918-0.996, p<0.001)$ among the three parameters. However, baseline ICP had evidently weaker predictive ability than PICGap (AUC $=0.782$ for baseline ICP, 95\% Cl: $0.693-0.781, p<0.001)$ and baseline CVP had the weakest ability to predict the responsiveness (AUC $=0.660$ for CVP, 95\% $\mathrm{Cl}: 0.560-0.760, p=0.004$ ). PICGap, the difference value between baseline ICP and CVP; ICP, intracranial pressure; AUC, area under curve; ROC, receiver operating characteristic.

\section{Supplementary Files}

This is a list of supplementary files associated with this preprint. Click to download.

- Flowchart.png 